\title{
Progranulin promotes neurite outgrowth and neuronal differentiation by regulating GSK-3 $\beta$
}

\author{
Xue Gao ${ }^{1 *}$, Alvin P. Joselin ${ }^{1,4^{*}}$, Lei Wang ${ }^{1 *}$, Amar Kar ${ }^{1}$, Payal Ray ${ }^{1}$, Andrew Bateman ${ }^{2}$, Alison M. Goate ${ }^{3}$, \\ Jane Y. Wu ${ }^{1 \bowtie}$ \\ ${ }^{1}$ Department of Neurology, Lurie Cancer Center, Center for Genetic Medicine Northwestern University Feinberg School of \\ Medicine, Chicago, IL 60611, USA \\ 2 Division of Experimental Medicine, McGill University, and Endocrine Research Laboratory, Royal Victoria Hospital, Montréal, \\ Québec, Canada \\ ${ }^{3}$ Department of Psychiatry, Washington University School of Medicine, St. Louis, MO 63110, USA \\ ${ }^{4}$ Present address: Cellular and Molecular Medicine, University of Ottawa, Ontario, Canada \\ \ Correspondence: jane-wu@northwestern.edu \\ Received May 6, 2010 Accepted June 4, 2010
}

\section{ABSTRACT}

Progranulin (PGRN) has recently emerged as a key player in a subset of frontotemporal dementias (FTD). Numerous mutations in the progranulin gene have been identified in patients with familial or sporadic frontotemporal lobar degeneration (FTLD). In order to understand the molecular mechanisms by which PGRN deficiency leads to FTLD, we examined activity of PGRN in mouse cortical and hippocampal neurons and in human neuroblastoma SH-SY5Y cells. Treatment of mouse neurons with PGRN protein resulted in an increase in neurite outgrowth, supporting the role of PGRN as a neurotrophic factor. PGRN treatment stimulated phosphorylation of glycogen synthase kinase-3 beta (GSK-3 $\beta$ ) in cultured neurons. Knockdown of PGRN in SH-SY5Y cells impaired retinoic acid induced differentiation and reduced the level of phosphorylated GSK-3 $\beta$. PGRN knockdown cells were also more sensitized to staurosporineinduced apoptosis. These results reveal an important role of PGRN in neurite outgrowth and involvement of GSK-3 $\beta$ in mediating PGRN activity. Identification of GSK-3 $\beta$ activation as a downstream event for PGRN signaling provides a mechanistic explanation for PGRN activity in the nervous system. Our work also suggest that loss of axonal growth stimulation during neural injury repair or deficits in axonal repair may contribute to neuronal damage or axonal loss in FTLD associated with
PGRN mutations. Finally, our study suggests that modulating GSK- $3 \beta$ or similar signaling events may provide therapeutic benefits for FTLD cases associated with PGRN mutations.

KEYWORDS progranulin, frontotemporal lobar degeneration, glycogen synthase kinase 3 beta (GSK-3 $\beta$ ), neurite outgrowth

\section{INTRODUCTION}

Frontotemporal lobar degeneration (FTLD) is one of the most common neurodegenerative diseases. Clinically FTLD is highly heterogeneous, manifesting as syndromes as diverse as frontotemporal dementia (FTD), semantic dementia (SD) and progressive non-fluent aphasia (PA) (Neary et al., 1988). FTLD patients often exhibit atrophy of the prefrontal and anterior temporal lobes. Neuropathologically, FTLD can be classified into two distinct groups based on immunohistochemical characteristics: either tau-positive pathology [such as Pick's disease (PD), corticobasal degeneration (CBD) and progressive supranuclear palsy (PSP)] or tau- and a-synuclein-negative but ubiquitin-positive intraneuronal inclusions (FTLD-U) (Cairns et al., 2007a; for recent reviews, see van Swieten and Heutink, 2008; Armstrong et al., 2010; Sleegers et al., 2010). The ubiquitin-positive inclusions are positive for TAR DNA binding protein-43 (TDP-43). Collectively, the neurodegenerative diseases displaying TDP-43

\footnotetext{
"These authors contributed equally to the work.
} 
positive pathology have been named TDP-43 proteinopathies (Arai et al., 2006; Neumann et al., 2006, 2007; Amador-Ortiz et al., 2007; Nakashima-Yasuda et al., 2007). The genetic etiology of FTLD-U is diverse. Several genes have been identified including vasolin-containing protein (VCP) (GuyantMarechal et al., 2006), charged multivesicular body protein 2B (CHMP2B) (Skibinski et al., 2005) and progranulin (PGRN). Mutations in PGRN account for approximately $10 \%$ of FTLD-U cases (Gass et al., 2006). Recent reports implicate PGRN in other neurodegenerative diseases such as Amyotrophic Lateral Sclerosis (ALS) (Sleegers et al., 2008), Parkinson's disease (PD) and Alzheimer's disease (AD) (Brouwers et al., 2007).

Progranulin, also known as acrogranin (Baba et al., 1993), granulin-epithelin precursor (Zanocco-Marani et al., 1999), proepithelin (Plowman et al., 1992) or PC cell-derived growth factor (PCDGF) (Zhou et al., 1993) is a 593 amino acid glycoprotein with an apparent molecular weight of approximately $88 \mathrm{kDa}$. PGRN contains 7.5 tandem repeats of a conserved granulin motif with 12 cysteinyl residues (Bateman et al., 1990; Bhandari et al., 1992). PGRN is a growth factor, widely expressed in different tissues and with a range of activities from neurodevelopment, wound repair, inflammation to tumor growth (He and Bateman, 1999; Zhu et al., 2002; Daniel et al., 2003).

A large number of mutations in $P G R N$ gene have been identified in patients with FTLD-U, in both familial and sporadic cases (Baker et al., 2006; Cruts et al., 2006; Gass et al., 2006; Pickering-Brown et al., 2006; Mukherjee et al., 2008). FTLD-U causing mutations in PGRN are distributed over the entire length of the gene. Most are missense, nonsense, frame-shift and splice site mutations (Mackenzie and Rademakers, 2007; Gijselinck et al., 2008). Non-sense, frame-shift and splice site mutations may cause premature termination of the coding sequence or degradation of the mutant RNA by nonsense-mediated decay. PGRN protein deficiency has been proposed as a disease mechanism (Baker et al., 2006; Cruts et al., 2006; Gass et al., 2006; Pickering-Brown et al., 2006; Mukherjee et al., 2008).

To define the biological activity of PGRN in neurons, we examined the effect of PGRN on mouse hippocampal and cortical neurons in primary culture. PGRN stimulated neurite outgrowth in primary neuronal culture. PGRN treatment increased phosphorylation of glycogen synthase kinase- $3 \beta$

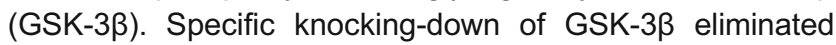
PGRN-stimulated neurite outgrowth, suggesting that GSK-3 $\beta$ is required for $P G R N$ signaling in neurons. We also examined PGRN function in stable SH-SY5Y cells in which PGRN expression was knocked down by a vector-based shRNA approach. PGRN is required for differentiation of SH-SY5Y cells. Significant changes in cellular signaling during differentiation were observed in cells with reduced expression of PGRN.

\section{RESULTS}

\section{PGRN promotes neurite outgrowth in cortical and hippocampal neurons}

To investigate the function of PGRN, we used mouse cortical and hippocampal neurons. Dissociated neurons were cultured on coverslips in the presence of purified protein at different concentrations. Treatment with purified PGRN $(20-50 \mathrm{ng} / \mathrm{mL})$ significantly stimulated neurite outgrowth (Fig. 1). The effect was dose-dependent (data not shown). Several PGRN mutants were also tested in the assay. Fig. 2A shows the Western blot analyses of the conditioned media using anti-GFP or a specific anti-PGRN antibody described previously (Ong et al., 2006). Consistent with published reports (Mukherjee et al., 2008; Shankaran et al., 2008), the A9D mutant was not detected in significant amounts in the conditioned media (Fig. 2A, lane 3) since the mutation in the signal peptide decreased secretion of the protein. Two truncation mutations associated with FTLD-U, R418X and W386X were also examined. A significant increase in neurite length was observed in primary neurons treated with wild-type PGRN but not FTLD-U associated mutants (A9D, R418X and W386X) in comparison to neurons treated with the control media (Fig. 2B). Quantification of the neurite length following immunostaining with the neuron-specific class III $\beta$-tubulin (TUJ1) antibody reveals an approximately 2 -fold increase in neurite length after PGRN treatment (Fig. 1A-D).

\section{PGRN stimulates phosphorylation of GSK-3 $\beta$ and AKT1}

The kinases GSK-3 $\beta$ and AKT play an important role in neurite outgrowth and in the establishment and the maintenance of axon-dendrite polarity in neurons (Jiang et al., 2005). GSK-3 $\beta$ is a well-known substrate of the serine/ threonine kinase AKT1/PKBa and phosphorylation of GSK-3 $\beta$ by activated AKT1 at Ser9 results in its inactivation (Cross et al., 1995). We examined the phosphorylation status of GSK$3 \beta$ in response to $P G R N$ treatment in mouse cortical neurons. Primary neurons were treated with purified PGRN or the control preparation. PGRN induced a significant increase in phosphorylation of GSK-3 $\beta$, AKT and ERK as shown by Western blotting (Fig. 3). These results suggest a role for PGRN in stimulating signaling changes resulting in phosphorylation and inactivation of GSK-3ß in cortical neurons.

\section{GSK-3 $\beta$ regulation is required for PGRN-induced neurite outgrowth}

To confirm the role of GSK-3 $\beta$ in mediating PGRN-induced neurite outgrowth, we used short hairpin RNA (shRNA) that

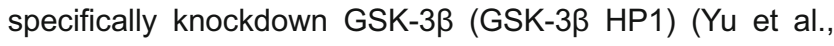
2003; Jiang et al., 2005). Cortical neurons were co-transfected 
using a plasmid for yellow fluorescent protein (YFP) and a plasmid expressing either the control shRNA or GSK-3 $\beta$ HP1. Similar to the results shown in Fig. 1, PGRN treatment of cortical neurons transfected with the control construct led to a significant increase in neurite outgrowth. However, transfection of the GSK-3 $\beta$ specific shRNA, but not the control shRNA, eliminated the activity of PGRN in stimulating neurite outgrowth (Fig. 4). These results support the involvement of GSK-3 $\beta$ in mediating PGRN activity in neurons.

\section{PGRN knockdown impairs differentiation of SH-SY5Y cells}

The spectrum of PGRN mutations reported in FTLD-U patients suggests that haploinsufficiency of PGRN function may result in neurodegeneration. To examine the effect of the loss of PGRN expression in human cells, we knocked down PGRN gene in neuroblastoma SH-SY5Y cells and generated stable knockdown cells. This human neuroblastoma cell line can be induced to differentiate into neuron-like cells by treatment with retinoic acid and BDNF. PGRN knockdown was achieved using pSUPERIOR RNAi constructs containing distinct target sequences corresponding to nucleotide sequences 207 to 226 and 1567 to 1588 specific for human PGRN gene. The vector control was also stably introduced into SH-SY5Y cells to generate the control cell line (Ctrl). After selecting cells for stable expression of the shRNA plasmid, individual clones were analyzed for PGRN expression. As shown in Fig. 5A, a significant reduction in PGRN protein expression was observed in several clones stably expressing the two shRNA target sequences in comparison with the control clone. Two representative clones from each group expressing a different target sequence were selected for further analysis.

A characteristic feature of the SH-SY5Y neuroblastoma cells is their ability to differentiate into cells with neuron-like morphology. To examine the role of PGRN in differentiation, the control and PGRN knockdown cells were treated with all-trans retinoic acid (RA) and human recombinant brain derived neurotrophic factor (BDNF). Following treatment with RA and BDNF for $7 \mathrm{~d}$, the control cells underwent morphological differentiation, displaying neuron-like features (Fig. 5B, top panel). Long neurites were formed in the

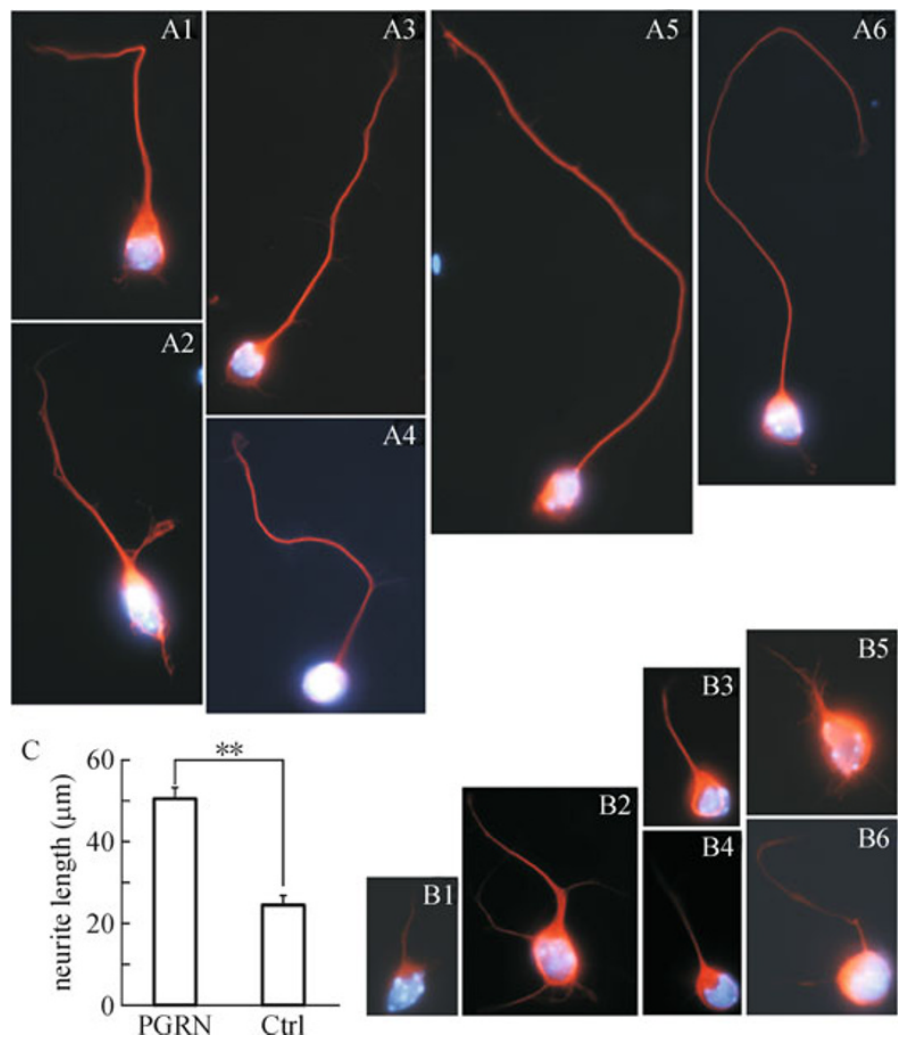

Figure 1. PGRN induces neurite outgrowth in primary cultures of mouse cortical neurons. Cortical neurons isolated from E15 embryos were treated with purified PGRN protein (PGRN, panels A1-A6) or vehicle control preparations (Ctrl, panels B1-B6) for 20 h. Neurites were stained with neuron-specific beta III tubulin and nuclei were visualized after staining with Hoechst dye. Six neurons are shown from either PGRN or control treated groups to demonstrate the range of neurite outgrowth effect. The average length of the longest neurite was quantified from 60 randomly selected neurons in each group. The data represent three independent experiments. The bar diagram represents mean values \pm SEM. 

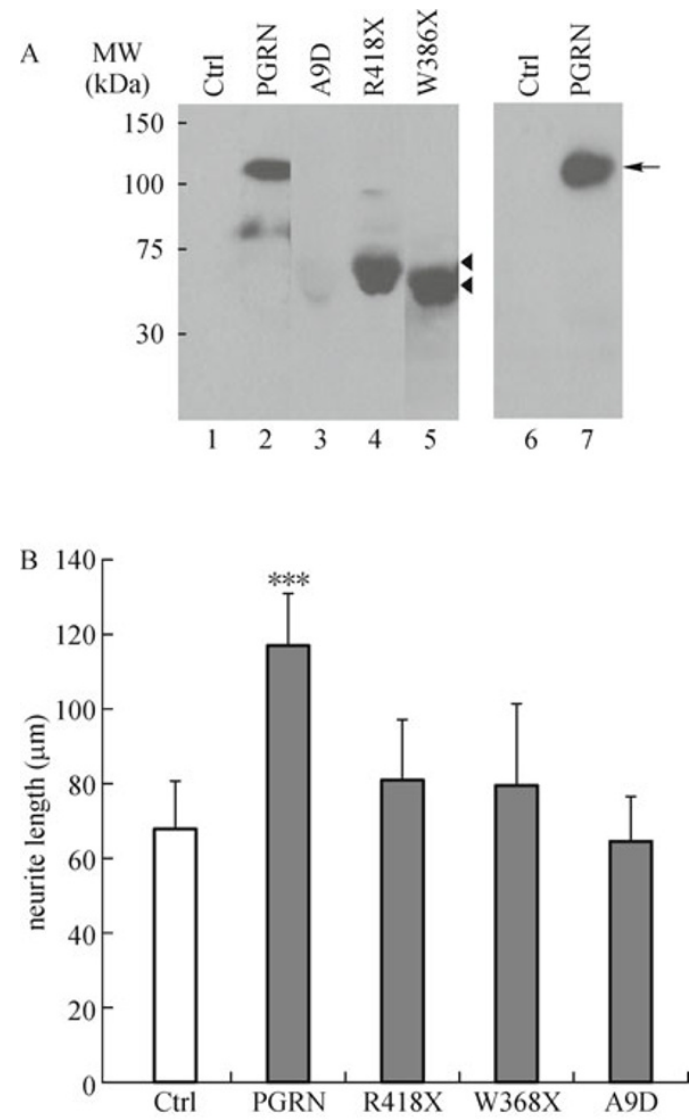

Figure 2. Wild-type, but not mutant, PGRN stimulates neurite outgrowth in primary cultures of mouse cortical neurons. (A) Analyses of the wild-type and mutant PGRN proteins by Western blotting. The wild-type and mutant PGRN proteins were expressed as GFP-tagged proteins in HEK293 cells. Conditioned media from HEK293 clones expressing the control vector (Ctrl), wild-type PGRN (PGRN) or the PGRN mutants A9D, R418X and W386X were collected and analyzed by western blotting using an anti-GFP antibody (lanes 1-5, respectively). The control or PGRN protein was detected by Western blotting using a PGRN specific antibody (lane 6 and 7 , respectively). (B) Quantification of axon outgrowth. Primary cultures of mouse cortical neurons were grown in the presence of conditioned media from the control (Ctrl), wild-type PGRN (PGRN) or PGRN mutants A9D, R418X and W386X expressing HEK293 cells. As compared with the control group, the wild type PGRN (PGRN), but not mutant PGRN proteins, significantly increased neurite length $\left({ }^{* * *} P<0.01\right)$. The average length of the longest neurite was quantified using ImageJ software from 60 randomly selected neurons in each group. The data represent three independent experiments. The bar diagram represents mean values \pm SEM.

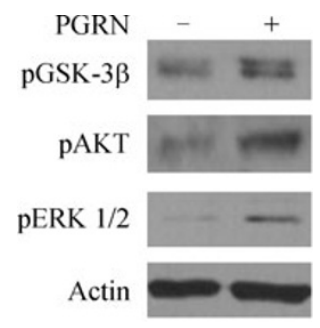

Figure 3. PGRN induces phosphorylation of GSK-3 $\beta$, AKT and ERK in mouse cortical neurons. Mouse cortical neurons were stimulated using the control preparation (-) or purified PGRN protein (+), and cell lysates were harvested and analyzed by Western blotting using specific antibodies as indicated. Western blotting using actin antibody shows that an equal level of proteins was loaded.
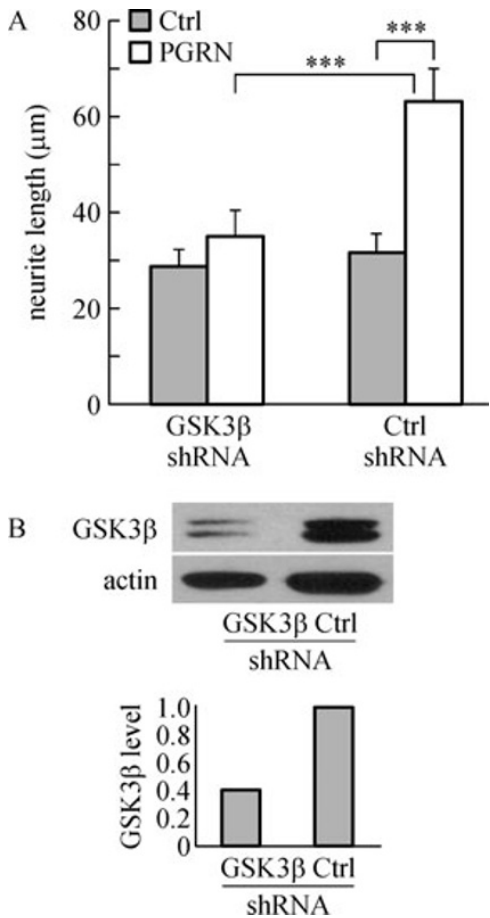

Figure 4. PGRN stimulated neurite outgrowth is repressed after GSK-3 $\beta$ knockdown. (A) Mouse cortical neurons were co-transfected with YFP and either a control shRNA or a GSK-3 $\beta$ specific shRNA. Neurons were then cultured in the presence of either the control (Ctrl) or purified PGRN for $20 \mathrm{~h}$, then fixed and immunostained using beta III tubulin antibody (Tuj1). Lengths of the Tuj1 staining neurites were quantified using the ImageJ software. The bar diagram represents mean values \pm SEM. Data were collected from three independent experiments. (B) The level of GSK-3 $\beta$ protein in the control or GSK-3 $\beta$ specific shRNA transfected cortical neurons as detected by Western blotting using GSK-3 $\beta$ specific antibody. Western blotting with actin antibody shows that an equivalent level of proteins was loaded. The lower panel shows the corresponding Western blot signals. 

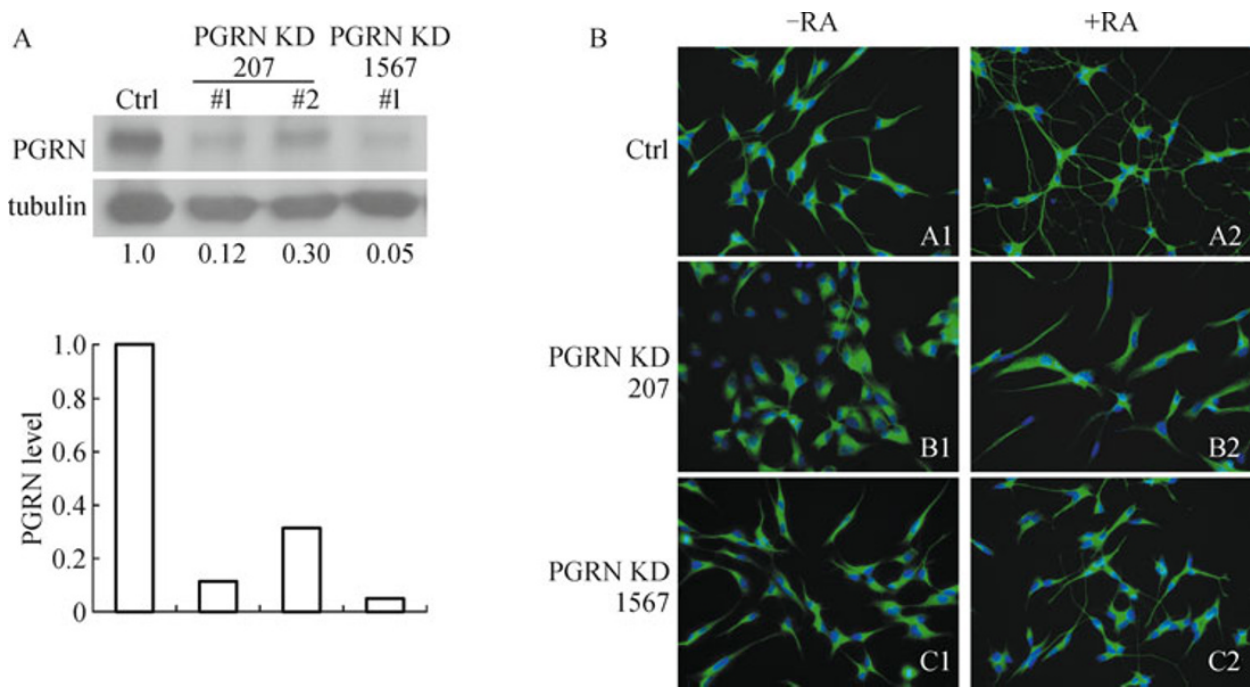

Figure 5. Knocking-down PGRN in SH-SY5Y neuroblastoma cells blocks retinoic acid induced differentiation. (A) Stable knockdown of PGRN in SH-SY5Y neuroblastoma cells. Whole cell extracts of SH-SY5Y clones expressing either the vector control (Ctrl) or two distinct target sequences of human PGRN mRNA (\#207 and \#1567) were analyzed for the expression of PGRN by Western blotting using a specific PGRN antibody. Tubulin levels were analyzed as loading controls. Lower panel represents the relative band intensity normalized to the corresponding tubulin band. (B) Effect of PGRN knockdown on retinoic acid induced differentiation of SH-SY5Y cells. Control (Ctrl) and two independent PGRN knockdown clones (\#207 and \#1567) were treated with vehicle control $(-\mathrm{RA})$ or $10 \mu \mathrm{M}$ all-trans retinoic acid and $50 \mathrm{ng} / \mathrm{mL}$ BDNF (+ RA) for $7 \mathrm{~d}$. Cells were immunostained using neuronsspecific beta III tubulin antibody Tuj1. Pictures are representative of multiple independent experiments. Nuclei were stained using Hoechst dye. In shRNA control cells, RA/BDNF induced differentiation with extensive formation of neurites. In PGRN KD cells, there was no detectable sign of differentiation after RA/BDNF treatment.

differentiating cells that expressed axonal markers such as Tau. In PGRN knockdown clones, however, such RA- and BDNF-induced differentiation was blocked, without detectable neurite outgrowth (Fig. 5B). Several PGRN knockdown clones all showed similar differentiation defective phenotype without responses to RA and BDNF treatment (data not shown).

\section{GSK-3 $\beta$ phosphorylation is reduced in differentiated SH-SY5Y cells with PGRN knockdown}

PGRN functions to stimulate neurite outgrowth in mouse cortical and hippocampal neurons by phosphorylating GSK$3 \beta$. We investigated the role of PGRN in GSK-3 $\beta$ activation during RA-induced differentiation using PGRN knockdown cells. Western blotting was performed in the control and PGRN knockdown cells following RA treatment for $7 \mathrm{~d}$. The level of tau protein in differentiated and undifferentiated $\mathrm{SH}$ SY5Y cells was determined as a marker of differentiation because its expression is increased in differentiated cells (Smith et al., 1995; Encinas et al., 2000; Jämsä et al., 2004). In the control cells, tau expression was increased after RAinduced differentiation (Fig. 6, compare lane 2 with 1). However, tau protein level was slightly reduced in PGRN knockdown clones (Fig. 6, compare lane 4 with 2), consistent with the lack of morphological changes in these PRGN

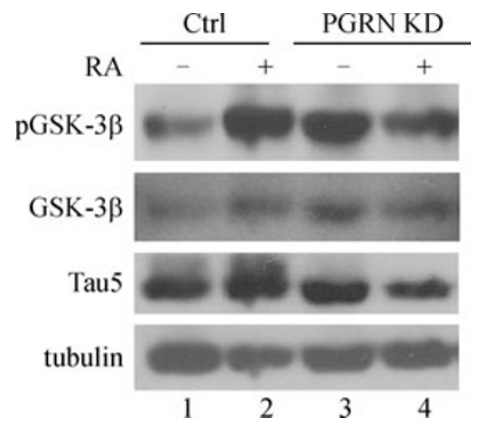

Figure 6. Retinoic acid induces GSK-3 $\beta$ phosphorylation in the control but not PGRN knockdown cells. The control (Ctrl) and PGRN knockdown (PGRN KD) cells were treated with vehicle control (-) or with $10 \mu \mathrm{M}$ retinoic acid $(+)$ for $7 \mathrm{~d}$. Cell lysates were harvested and analyzed by Western blotting using specific antibodies against Tau (Tau5), total GSK-3 $\beta$

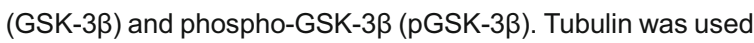
as a loading control.

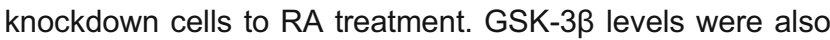
examined in these PGRN knockdown cells. Western blot analyses showed that phospho-GSK-3 $\beta$ was increased after RA-induced differentiation in the control cells. In the PGRN knockdown cells, however, a slight decrease in pGSK-3 $\beta$ level was observed after RA-induced differentiation (Fig. 6). 
These results further confirm that in SH-SY5Y cells with PGRN knockdown are deficient in differentiation responses to RA-treatment.

\section{PGRN knockdown cells show increased susceptibility to apoptosis}

The neuropathology of FTLD is characterized by atrophy of the frontal and temporal lobes and degeneration of the corpus striatum (Mann, 1998). Studies from a number of neurodegenerative diseases suggest a role of caspase activation and apoptosis in neurodegeneration (Yang et al., 1998; Gervais et al., 1999; Rohn et al., 2001, 2002; Cotman et al., 2005). PGRN knockdown cells did not show obvious increase in cell death under the normal culture conditions. However, PGRN knockdown rendered cells more susceptible to apoptosis when cell death was induced using a protein kinase inhibitor staurosporine. We compared the control or PGRN knock-
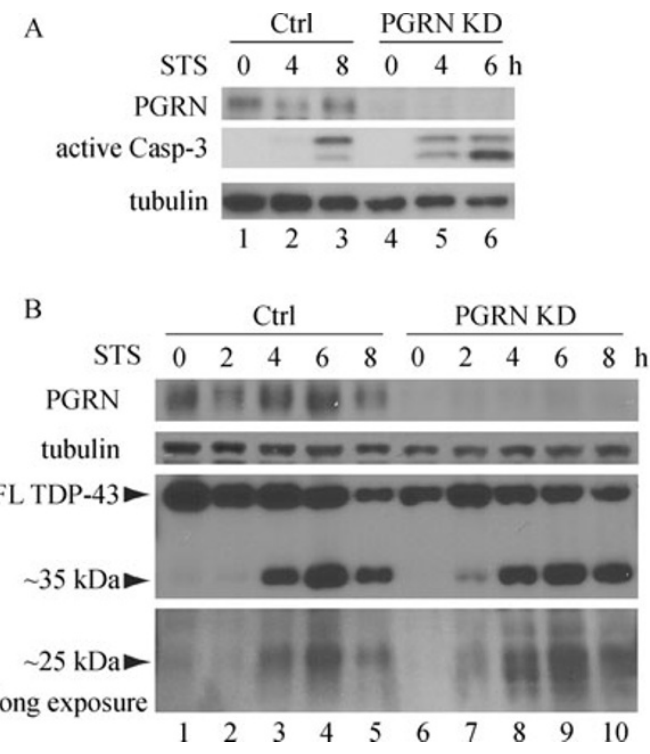

Figure 7. PGRN knockdown sensitizes cells to staurosporine-induced apoptosis. Apoptotic cell death was induced using $1 \mu \mathrm{M}$ staurosporine (STS) in control (Ctrl) or PGRN knockdown (PGRN KD) SH-SY5Y cells. Cell extracts were prepared at the indicated time points following STS treatment and analyzed by Western blotting using specific antibodies against PGRN and TDP-43. Arrowheads indicate the full-length TDP-43 (FL-TDP-43) and caspase cleavage fragments of approximate molecular weight 35 and $25 \mathrm{kDa}$. (A) shows that in PGRN knockdown cells, active caspase- 3 began to appear at $4 \mathrm{~h}$ after STS treatment, as compared to $8 \mathrm{~h}$ in the control cells, indicating accelerated apoptosis in PGRN knockdown cells. (B) PGRN knockdown accelerated cleavage of TDP-43. In control cells TDP-43 cleavage products were detectable by $4 \mathrm{~h}$ after STS treatment, whereas in PGRN knockdown cells these bands appeared $2 \mathrm{~h}$ after STS treatment with an increase in the level of $25 \mathrm{kDa}$ fragment. down cells and analyzed activation of caspase- 3 and cleavage of TDP-43, a caspase substrate and an important player in FTLD-U. Western blot analysis shows an earlier activation of caspase-3 in the PGRN knockdown cells after apoptosis induction by staurosporine (Fig. 7). A significantly higher level of active caspase- 3 was detected $4 \mathrm{~h}$ after apoptosis induction in the PGRN knockdown cells as compared to the control cells (compare lanes 2 and 5, Fig. 7A). This is also reflected in the cleavage of TDP-43, a known caspase-3 substrate involved in FTLD-U (Fig. 7B, lanes 2, 3 and 7,8 ). Interestingly, in correlation with caspase-3 activation, significantly higher levels of the $\sim 25 \mathrm{kDa}$ fragment of TDP-43 was also detected in PGRN knockdown cells. These results support that reduced PGRN expression led to sensitization of SH-SY5Y cells to staurosporine-induced apoptosis.

\section{DISCUSSION}

PGRN is an autocrine growth factor displaying mitogenic potential cells (Plowman et al., 1992; Zhou et al., 1993) and promotes tumor growth (He and Bateman, 1999). PGRN is also a mediator of wound response (He et al., 2003). Recent studies have identified more than 60 mutations in $P G R N$ gene in FTLD-U families et al (Gijselinck et al., 2008), indicating a critical role of PGRN in the pathogenesis of FTLD-U (for reviews see Sleegers et al., 2010). Some mutations are predicted to result in premature termination possibly leading to nonsense mediated mRNA decay (NMD), whereas other mutations may generate truncated proteins with defective function. It has been proposed that the disease phenotype may be a result of PGRN haploinsufficiency due to a reduction in the level of functional PGRN protein.

To understand the functional role of PGRN in neurons, we examined the effects of exogenous progranulin on mouse cortical and hippocampal neurons and of PGRN knockdown in the human neuroblastoma cell line SH-SY5Y. Mouse cortical and hippocampal neurons treated with PGRN protein developed significantly longer neurites as compared with the control treated neurons (Fig. 1 and 2; data not shown). This result is consistent with a recent report published while our study was under progress that PGRN and its proteolytic fragment of PGRN, GRN E, increased neuronal survival and neurite outgrowth (Van Damme et al., 2008). Conditioned media from the secretion mutant $A 9 D$ or the nonsense mutations resulting in truncation of PGRN, R418X and W386X, did not affect neurite outgrowth (Fig. 2). PGRN treatment increased the phospho-GSK-3 $\beta$ level in the cultured neurons. Interestingly, knocking down GSK-3 $\beta$ expression using the specific shRNA resulted in the loss of $P G R N$-induced neurite outgrowth, suggesting that GSK- $3 \beta$ is required for mediating PGRN activity in stimulating neurite outgrowth.

In cultured neurons, the increase in pGSK-3ß induced by 
PGRN treatment correlated with an increase in PAKT level (Fig. 3), suggesting that PGRN may use the AKT-GSK-3 $\beta$ pathway. In this regard, PGRN signaling is similar to other growth factors in activating the AKT-GSK-3 $\beta$ pathway involved in cell survival (Zhou et al., 1993; He and Bateman, 1999). The AKT and ERK pathways are activated during growth factor induced cell migration (Delehedde et al., 2001). PGRN function in neurons and non-neuronal cells may share similar signal transduction pathways.

In our study, PGRN stimulation of neurite outgrowth was eliminated when GSK-3 $\beta$ was knocked down by specific shRNA (Fig. 4). A previous study has shown that treatment of cortical neurons with GSK-3 $\beta$ pharmacological inhibitors or knockdown of GSK-3 $\beta$ affect neuronal differentiation and establishment of neuronal polarity (Jiang et al., 2005). It should be noted that we have not obtained consistent picture whether PGRN treatment affects the establishment or maintenance of neuronal polarity, although we have attempted different conditions including treatment timing or duration.

A recent study also reported that treatment of dorsal root ganglion (DRG) neurons with pharmacological inhibitors of GSK-3 $\beta$ resulted in loss of neurite outgrowth (Dill et al., 2008). Our results together with several previous studies that employ GSK-3 $\beta$ inhibitors (Eickholt et al., 2002; Jiang et al., 2005; Yoshimura et al., 2005; Dill et al., 2008) support that GSK-3 $\beta$ plays an important role in neurite outgrowth. GSK-3 $\beta$ phosphorylation and inactivation of GSK-3 $\beta$ lead to enhanced neurite outgrowth. On the other hand, inhibition of GSK-3 $\beta$ activity by pharmacological inhibitors of GSK-3 $\beta$ or knockdown of GSK-3 $\beta$ can result in a loss of regulatable GSK-3 $\beta$ and therefore, a loss of stimulated neurite outgrowth. It is conceivable that a basal level of GSK-3 $\beta$ expression is required for neurite outgrowth especially in response to growth factor stimulation. Consistent with this, regulation of GSK-3 $\beta$ substrates was associated with morphological changes in neurons (Kim et al., 2006). Complete suppression of GSK-3 $\beta$ resulted in inhibition of axon growth. Taken together, our observations in mouse cortical neurons suggest a functional role for GSK-3 $\beta$ regulation in response to PGRN stimulation. Our work also suggests that loss of axonal growth stimulation during neural injury repair or deficits in axonal repair may contribute to neuronal damage or axonal loss in FTLD associated with PGRN mutations. Identification of GSK-3 $\beta$ activation as a signaling event in PGRN function in neurons provides a mechanistic explanation for PGRN activity in the nervous system. It is possible that loss of axonal growth stimulation during neural injury repair or deficits in axonal repair may contribute to neuronal damage or axonal loss in FTLD associated with PGRN mutations.

In addition to its role in neurite outgrowth in mouse cortical neurons, we analyzed the effect of PGRN in neuronal differentiation by knocking-down PGRN in the human neuroblastoma cell line SH-SY5Y. We established PGRN knockdown stable cell lines to avoid variation in transient transfections. Retinoic acid induced responses, including neurite outgrowth, morphological changes and changes in tau expression, were defective in these PGRN knockdown cells. Therefore, PGRN is required for RA-induced differentiation of $\mathrm{SH}-\mathrm{SY} 5 \mathrm{Y}$ cells. This result also suggests that PGRN may act in an autocrine fashion in neurons, similar to that in 3 T3 cells or tumor cells (Plowman et al., 1992; Zhou et al., 1993; He and Bateman, 1999).

Analysis of the molecular signaling changes during differentiation in PGRN knockdown cells revealed significant differences in the level of phosphorylated GSK-3 $\beta$. In the

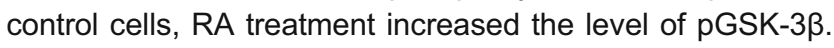
However, in PGRN knockdown cells, the level of pGSK-3 $\beta$ was slightly decreased following RA-treatment. This is consistent with the observation in the cortical neurons in which pGSK-3 $\beta$ was increased after PGRN treatment. GSK-3 $\beta$ regulates multiple signaling pathways. Enhanced GSK-3 $\beta$ activity has been associated with other neurodegenerative diseases such as Alzheimer's disease (Takashima et al., 1993; Phiel et al., 2003; Fuentealba et al., 2004; Ferrer et al., 2005), Parkinson's disease (King et al., 2001) and ALS (Koh et al., 2005). GSK-3 $\beta$ has also been implicated in the activation of the mitochondria-mediated apoptotic pathway in response to multiple stimuli (reviewed in Beurel and Jope, 2006). Our observation of sensitization of the PGRN knockdown cells to staurosporine-induced apoptosis also supports the association of reduced pGSK-3 $\beta$ or increased GSK-3 $\beta$ activity with apoptosis.

Together with the published observation of the neurotrophic effect of PGRN (Van Damme et al., 2008), our results suggest that a loss of PGRN function in FTLD-U patients may result in defects in neural differentiation. Progressive loss of neuronal polarity has been proposed for neurodegenerative diseases such as Alzheimer's disease. While our work was in progress, progranulin-deficient mice were reported to show greater activation of microglia and astrocytes with accumulated cytosolic phosphorylated TDP-43 in hippocampal and thalamic regions (Yin et al., 2010), although it remains to be determined whether neural repair in such mice is defective.

Our study shows that cells with reduced PGRN expression display increased sensitivity to staurosporine-induced cell death, suggesting a neuroprotective activity of PGRN. It is conceivable that in FTLD-U patients, certain neurons may be more prone to death in the absence of the protective functions of PGRN. Interestingly, cleavage of TDP-43 and formation of $\sim 25 \mathrm{kDa}$ fragment of TDP-43 were also increased in PGRNknockdown cells when cell death was induced. Although it was reported that reduced PGRN expression had no effect on TDP-43 cleavage (Shankaran et al., 2008), other groups also observed the effect of PGRN on TDP-43 cleavage (Zhang et al., 2007), similar to our study. In FTLD-U patients, it remains 
to be determined whether TDP-43 cleavage is a cause or a consequence of cell death.

Our results suggest that at least two mechanisms may contribute to PGRN haploinsufficiency in patients with PGRN mutations: a reduction in neural differentiation and a decrease in neuroprotection. Decreased neural repair has been reported in mouse models of neurodegenerative diseases such as Alzheimer's disease (Verret et al., 2007) and Parkinson's disease (Winner et al., 2008). PGRN may play a role in neural repair, particularly in regions affected in FTLD-U. PGRN is widely expressed in the neuroepithelium during early neural development but its expression is limited to defined neuronal cell populations, such as the cortical and hippocampal pyramidal neurons and Purkinje cells in the adult brain (Daniel et al., 2000, 2003). Further studies are necessary to elucidate the molecular mechanisms underlying PGRN function in the normal brain and under pathological conditions.

\section{MATERIALS AND METHODS}

\section{Plasmids, antibodies and reagents}

Two different target sequences of 19 nucleotides targeted against nucleotides 207-226 (\#207) and 1567-1588 (\#1567) of the PGRN mRNA were designed. The 64 nt short hairpin RNA sense and antisense primer sequences for \#207 were 5'-GATCCCCGGCCACTCCTGCATCTTTATTCAAGAGATAAAGATGCAGGAGTGGCCTTTTTGGAAA-3' and 5'-AGCTTTTCCAAAAAGGCCACTCCTGCATCTTTATCTCTTGAATAAAGATGCAGGAGTGGCCGGG-3'. The sense and antisense primer pair for \#1567 were 5'-GATCCCCGGACACTTCTGCCATGATATTCAAGAGATATCATGGCAGAAGTGTCCTTTTTGGAAA-3' and 5'-AGCTTTTCCAAAAAGGACACTTCTGCCATGATATCTCTTGAATATCATGGCAGAAGTGTCCGGg-3'. The sense and antisense primer pairs were annealed and ligated into the pSUPERIOR vector (OligoEngine) according to manufacturer's instructions.

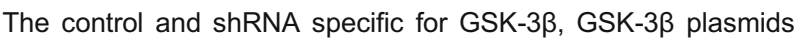
(wild type and S9A mutant) were as described in Jiang et al. (2005). The following antibodies and chemicals were employed in this study: PGRN (PCDGF, Zymed), Neuron specific beta III tubulin, GSK-3 $\beta$, phospho-GSK-3 $\beta$ (Cell Signaling), phospho-Akt (ser 473) (Cell Signaling), Erk 1/2, Tau5, actin (Calbiochem), tubulin, SB216763 and SB415286 (Tocris), and LiCl (Sigma).

\section{Purification of PGRN}

HEK293 cells expressing vector control or $6 \times$ His-GFP-tagged PGRN were grown to confluence in DMEM supplemented with $10 \%$ FBS, 100 units $/ \mathrm{mL}$ penicillin and $0.1 \mathrm{mg} / \mathrm{mL}$ streptomycin (Gibco). Medium was changed to serum free DMEM/F-12 for $24 \mathrm{~h}$. Conditioned medium was collected and diluted with phosphate buffered saline (PBS). The final concentration was adjusted to $20 \%$ glycerol (Sigma), 0.1\% Triton X-100 (Sigma) and $100 \mathrm{mM}$ imidazole. Nickelagarose beads (Qiagen) were equilibrated in PBS containing $0.1 \%$ Triton X-100 and $100 \mathrm{mM}$ imidazole. The beads were then incubated with conditioned medium for $4 \mathrm{~h}$ at $4^{\circ} \mathrm{C}$. PGRN was eluted from the beads with buffer $B$ (PBS containing $0.1 \%$ Triton X-100 and $500 \mathrm{mM}$ imidazole). The peak fractions were dialyzed against PBS, and purified PGRN protein was stored in aliquots at $80^{\circ} \mathrm{C}$ until use.

\section{Cell culture and transfection}

All SH-SY5Y clones were maintained in F12: Dulbecco's modified Eagle's medium (DMEM) 1:1 (Gibco), supplemented with $10 \%$ fetal bovine serum, 100 units $/ \mathrm{mL}$ Penicillin and $0.1 \mathrm{mg} / \mathrm{mL}$ streptomycin (Gibco). Cells were transfected using Fugene 6 (Roche) according to manufacturer's instruction. $24 \mathrm{~h}$ post transfection, the transfected cells were selected using geneticin G418 (Gibco). Single clones were isolated, characterized and used for experiments.

Dissociated primary neurons were cultured essentially as described previously (Liu et al., 2004) with modifications. Briefly, embryos were removed from timed-pregnant mice at E15 (for cortical neurons) or E18 (for hippocampal neurons). Mouse brains were dissected in cold Hank's buffered salt solution (Gibco). The cortex or hippocampus was cut into small pieces and trypsinized for $15 \mathrm{~min}$ at $37^{\circ} \mathrm{C}$. The dissociated neurons were resuspended in DMEM supplemented with heat-inactivated FBS and 20 units $/ \mathrm{mL}$ of penicillin/streptomycin. Cells were grown on dishes or coverslips coated overnight with $100 \mu \mathrm{g} / \mathrm{mL}$ poly-L-lysine (PLL) and $5 \mu \mathrm{g} / \mathrm{mL}$ laminin at $37^{\circ} \mathrm{C}$ in a $5 \% \mathrm{CO}_{2}$ incubator. Cells were then used for Western blotting, immunostaining or biochemical analyses.

For transfection of GSK-3 $\beta$ shRNA constructs, dissociated cortical neurons from $\mathrm{E} 15$ mice $\left(4 \times 10^{6}\right.$ neurons per group) were mixed with YFP and either control or GSK-3 $\beta$ shRNA constructs (Jiang et al., 2005) and immediately placed in the nucleofection cuvette (Amaxa Biosystems). After electroporation (O-005 program), cells were diluted in prewarmed DMEM supplemented with 10\% FBS and plated on coverslips coated with PLL and laminin at 50,000 cells per well. Cells were cultured for $24 \mathrm{~h}$ in the presence of the control or PGRN protein and then fixed with $4 \%$ paraformaldehyde for $10 \mathrm{~min}$, preincubated with $5 \%$ BSA in PBS with $0.1 \%$ Triton X-100 and stained using a monoclonal antibody specific for neuronal beta III tubulin. Nuclei were visualized after staining with Hoechst dye (Sigma).

\section{Axon outgrowth assay}

To analyze neurite outgrowth, E15 cortical neurons or E18 hippocampal neurons were dissociated as described above. Neurons were cultured in DMEM with $10 \%$ FBS for $2 \mathrm{~h}$. The culture media was changed to DMEM supplemented with B27 and penicillin/streptomycin. Neurons were treated with either conditioned media or the purified PGRN protein or the control mock preparation at $37^{\circ} \mathrm{C}$ with $5 \% \mathrm{CO}_{2}$ for $20 \mathrm{~h}$. Neurons were cultured and stained as described above. Quantification was performed using NIH ImageJ software.

Primary cortical neurons were cultured for $24 \mathrm{~h}$, serum starved overnight in $0.1 \%$ BSA (Roche) containing DMEM, then stimulated with PGRN or control purified protein at $37^{\circ} \mathrm{C}$ for $10 \mathrm{~min}$, immediately lysed with MLB lysis buffer (1\% Triton X-100, $50 \mathrm{mM}$ Tris, $\mathrm{pH} 7.4$, $150 \mathrm{mM} \mathrm{NaCl}, 10 \%$ glycerol, $10 \mathrm{mM} \mathrm{MgCl}_{2}$ and protease inhibitor mixture (Roche). Lysate were boiled with $2 \times$ SDS sample buffer (375 mM Tris (pH 6.8), 60\% glycerol, 12\% SDS, $864 \mathrm{mM} \mathrm{2-}$ mercaptoethanol, $0.05 \%$ bromophenol blue) for $1 \mathrm{~min}$ and were then separated by sodium dodecyl sulphate polyacrylamide gel electrophoresis (SDS-PAGE). Proteins were transferred to nitrocellulose membrane at $100 \mathrm{~V}$ for $1 \mathrm{~h}$ and blocked with $5 \%$ skim milk for $1 \mathrm{~h}$ at room temperature. Membranes were incubated overnight with the corresponding primary antibodies in $3 \% \mathrm{BSA}$ at $4^{\circ} \mathrm{C}$ followed by 
detection using HRP-conjugated secondary antibodies with chemiluminescence solution from GE Biosciences.

\section{Differentiation of and apoptosis induction in SH-SY5Y cells}

For differentiation, $1 \times 10^{4} \mathrm{SH}-\mathrm{SY} 5 \mathrm{Y}$ cells were grown overnight on coverslips pre-coated with $100 \mu \mathrm{g} / \mathrm{mL}$ PLL in 24-well plates. Differentiation was induced by treating cells with $10 \mu \mathrm{M}$ all-trans retinoic acid (RA) and $50 \mu \mathrm{g} / \mathrm{mL}$ brain-derived neurotrophic factor (BDNF) for 7 days in Neurobasal media supplemented with B27, GlutaMax and 100 units $/ \mathrm{mL}$ Penicillin and $0.1 \mathrm{mg} / \mathrm{mL}$ streptomycin (Invitrogen), with fresh media added every three days. Cells were fixed with $4 \%$ paraformaldehyde, permeabilized with $0.1 \%$ Triton $X$ 100 and stained as described above. For Western blotting, $1 \times 10^{5}$ cells were seeded in a $60-\mathrm{mm}$ culture plate and differentiation was induced with $10 \mu \mathrm{M}$ retinoic acid as described. For apoptosis induction, cells grown in $60 \mathrm{~mm}$ dishes were starved overnight in DMEM:F12 supplemented with B27. Staurosporine was added to a final concentration of $1 \mu \mathrm{M}$ and incubated different period $\mathrm{s}$ of time. Total cell lysates were collected at different time points and analyzed by Western blotting.

\section{ACKNOWLEDGEMENTS}

We thank the members of Wu laboratory for helpful discussion and critical reading of the manuscript. The work in the $\mathrm{Wu}$ lab was supported by NIH (JYW), JSMF (to JYW) James S. McDonnell Foundation Research Award (to JYW) and by Searle Foundation (to JYW).

\section{ABBREVIATIONS}

PGRN, Progranulin; FTLD, frontotemporal lobar degeneration; GSK$3 \beta$, glycogen synthase kinase 3 beta; STS, staurosporine

\section{REFERENCES}

Amador-Ortiz, C., Lin, W.L., Ahmed, Z., Personett, D., Davies, P., Duara, R., Graff-Radford, N.R., Hutton, M.L., and Dickson, D.W. (2007). TDP-43 immunoreactivity in hippocampal sclerosis and Alzheimer's disease. Ann Neurol 61, 435-445.

Arai, T., Hasegawa, M., Akiyama, H., Ikeda, K., Nonaka, T., Mori, H., Mann, D., Tsuchiya, K., Yoshida, M., Hashizume, Y., et al. (2006). TDP-43 is a component of ubiquitin-positive tau-negative inclusions in frontotemporal lobar degeneration and amyotrophic lateral sclerosis. Biochem Biophys Res Commun 351, 602-611.

Armstrong, R.A., Ellis, W., Hamilton, R.L., Mackenzie, I.R., Hedreen, J., Gearing, M., Montine, T., Vonsattel, J.P., Head, E., Lieberman, A.P., et al. (2010). Neuropathological heterogeneity in frontotemporal lobar degeneration with TDP-43 proteinopathy: a quantitative study of 94 cases using principal components analysis. J Neural Transm 117, 227-239.

Baba, T., Hoff, H.B. 3rd, Nemoto, H., Lee, H., Orth, J., Arai, Y., and Gerton, G.L. (1993). Acrogranin, an acrosomal cysteine-rich glycoprotein, is the precursor of the growth-modulating peptides, granulins, and epithelins, and is expressed in somatic as well as male germ cells. Mol Reprod Dev 34, 233-243.

Baker, M., Mackenzie, I.R., Pickering-Brown, S.M., Gass, J., Rade- makers, R., Lindholm, C., Snowden, J., Adamson, J., Sadovnick, A.D., Rollinson, S., et al. (2006). Mutations in progranulin cause tau-negative frontotemporal dementia linked to chromosome 17. Nature 442, 916-919.

Bateman, A., Belcourt, D., Bennett, H., Lazure, C., and Solomon, S. (1990). Granulins, a novel class of peptide from leukocytes. Biochem Biophys Res Commun 173, 1161-1168.

Beurel, E., and Jope, R.S. (2006). The paradoxical pro- and antiapoptotic actions of GSK3 in the intrinsic and extrinsic apoptosis signaling pathways. Prog Neurobiol 79, 173-189.

Bhandari, V., Palfree, R.G., and Bateman, A. (1992). Isolation and sequence of the granulin precursor cDNA from human bone marrow reveals tandem cysteine-rich granulin domains. Proc Natl Acad Sci U S A 89, 1715-1719.

Brouwers, N., Nuytemans, K., van der Zee, J., Gijselinck, I., Engelborghs, S., Theuns, J., Kumar-Singh, S., Pickut, B.A., Pals, P., Dermaut, B., et al. (2007). Alzheimer and Parkinson diagnoses in progranulin null mutation carriers in an extended founder family. Arch Neurol 64, 1436-1446.

Cairns, N.J., Bigio, E.H., Mackenzie, I.R., Neumann, M., Lee, V.M., Hatanpaa, K.J., White, C.L. 3rd, Schneider, J.A., Grinberg, L.T., Halliday, G., et al, and the Consortium for Frontotemporal Lobar Degeneration. (2007a). Neuropathologic diagnostic and nosologic criteria for frontotemporal lobar degeneration: consensus of the Consortium for Frontotemporal Lobar Degeneration. Acta Neuropathol 114, 5-22.

Cotman, C.W., Poon, W.W., Rissman, R.A., and Blurton-Jones, M. (2005). The role of caspase cleavage of tau in Alzheimer disease neuropathology. J Neuropathol Exp Neurol 64, 104-112.

Cross, D.A., Alessi, D.R., Cohen, P., Andjelkovich, M., and Hemmings, B.A. (1995). Inhibition of glycogen synthase kinase-3 by insulin mediated by protein kinase B. Nature 378, 785-789.

Cruts, M., Gijselinck, I., van der Zee, J., Engelborghs, S., Wils, H., Pirici, D., Rademakers, R., Vandenberghe, R., Dermaut, B., Martin, J.J., et al. (2006). Null mutations in progranulin cause ubiquitinpositive frontotemporal dementia linked to chromosome 17q21. Nature 442, 920-924.

Daniel, R., Daniels, E., He, Z., and Bateman, A. (2003). Progranulin (acrogranin/PC cell-derived growth factor/granulin-epithelin precursor) is expressed in the placenta, epidermis, microvasculature, and brain during murine development. Dev Dyn 227, 593-599.

Daniel, R., He, Z., Carmichael, K.P., Halper, J., and Bateman, A. (2000). Cellular localization of gene expression for progranulin. J Histochem Cytochem 48, 999-1009.

Delehedde, M., Sergeant, N., Lyon, M., Rudland, P.S., and Fernig, D. G. (2001). Hepatocyte growth factor/scatter factor stimulates migration of rat mammary fibroblasts through both mitogenactivated protein kinase and phosphatidylinositol 3-kinase/Akt pathways. Eur J Biochem 268, 4423-4429.

Dill, J., Wang, H., Zhou, F., and Li, S. (2008). Inactivation of glycogen synthase kinase 3 promotes axonal growth and recovery in the CNS. J Neurosci 28, 8914-8928.

Eickholt, B.J., Walsh, F.S., and Doherty, P. (2002). An inactive pool of GSK-3 at the leading edge of growth cones is implicated in Semaphorin 3A signaling. J Cell Biol, 157, 211-217.

Encinas, M., Iglesias, M., Liu, Y., Wang, H., Muhaisen, A., Ceña, V., Gallego, C., and Comella, J.X. (2000). Sequential treatment of SHSY5Y cells with retinoic acid and brain-derived neurotrophic factor 
gives rise to fully differentiated, neurotrophic factor-dependent, human neuron-like cells. J Neurochem 75, 991-1003.

Ferrer, I., Gomez-Isla, T., Puig, B., Freixes, M., Ribé, E., Dalfó, E., and Avila, J. (2005). Current advances on different kinases involved in tau phosphorylation, and implications in Alzheimer's disease and tauopathies. Curr Alzheimer Res 2, 3-18.

Fuentealba, R.A., Farias, G., Scheu, J., Bronfman, M., Marzolo, M.P., and Inestrosa, N.C. (2004). Signal transduction during amyloidbeta-peptide neurotoxicity: role in Alzheimer disease. Brain Res Brain Res Rev 47, 275-289.

Gass, J., Cannon, A., Mackenzie, I.R., Boeve, B., Baker, M., Adamson, J., Crook, R., Melquist, S., Kuntz, K., Petersen, R., et al. (2006). Mutations in progranulin are a major cause of ubiquitinpositive frontotemporal lobar degeneration. Hum Mol Genet 15, 2988-3001.

Gervais, F.G., Xu, D., Robertson, G.S., Vaillancourt, J.P., Zhu, Y., Huang, J., LeBlanc, A., Smith, D., Rigby, M., Shearman, M.S., et al. (1999). Involvement of caspases in proteolytic cleavage of Alzheimer's amyloid-beta precursor protein and amyloidogenic A beta peptide formation. Cell 97, 395- 406.

Gijselinck, I., Van Broeckhoven, C., and Cruts, M. (2008). Granulin mutations associated with frontotemporal lobar degeneration and related disorders: An update. Hum Mutat 29, 1373-1386.

Guyant-Maréchal, L., Laquerrière, A., Duyckaerts, C., Dumanchin, C., Bou, J., Dugny, F., Le Ber, I., Frébourg, T., Hannequin, D., and Campion, D. (2006). Valosin-containing protein gene mutations: clinical and neuropathologic features. Neurology 67, 644-651.

He, Z., and Bateman, A. (1999). Progranulin gene expression regulates epithelial cell growth and promotes tumor growth in vivo. Cancer Res 59, 3222-3229.

He, Z., Ong, C.H., Halper, J., and Bateman, A. (2003). Progranulin is a mediator of the wound response. Nat Med 9, 225-229.

Jämsä, A., Hasslund, K., Cowburn, R.F., Bäckström, A., and Vasänge, M. (2004). The retinoic acid and brain-derived neurotrophic factor differentiated SH-SY5Y cell line as a model for Alzheimer's disease-like tau phosphorylation. Biochem Biophys Res Commun 319, 993-1000.

Jiang, H., Guo, W., Liang, X., and Rao, Y. (2005). Both the establishment and the maintenance of neuronal polarity require active mechanisms: critical roles of GSK-3beta and its upstream regulators. Cell 120, 123-135.

Kim, W.Y., Zhou, F.Q., Zhou, J., Yokota, Y., Wang, Y.M., Yoshimura, T., Kaibuchi, K., Woodgett, J.R., Anton, E.S., and Snider, W.D. (2006). Essential roles for GSK-3s and GSK-3-primed substrates in neurotrophin-induced and hippocampal axon growth. Neuron 52, 981-996.

King, T.D., Bijur, G.N., and Jope, R.S. (2001). Caspase-3 activation induced by inhibition of mitochondrial complex I is facilitated by glycogen synthase kinase-3beta and attenuated by lithium. Brain Res 919, 106-114.

Koh, S.H., Lee, Y.B., Kim, K.S., Kim, H.J., Kim, M., Lee, Y.J., Kim, J., Lee, K.W., and Kim, S.H. (2005). Role of GSK-3beta activity in motor neuronal cell death induced by G93A or A4V mutant hSOD1 gene. Eur J Neurosci 22, 301-309.

Liu, G., Beggs, H., Jürgensen, C., Park, H.T., Tang, H., Gorski, J., Jones, K.R., Reichardt, L.F., Wu, J., and Rao, Y. (2004). Netrin requires focal adhesion kinase and Src family kinases for axon outgrowth and attraction. Nat Neurosci 7, 1222-1232.
Mackenzie, I.R., and Rademakers, R. (2007). The molecular genetics and neuropathology of frontotemporal lobar degeneration: recent developments. Neurogenetics 8, 237-248.

Mann, D.M. (1998). Dementia of frontal type and dementias with subcortical gliosis. Brain Pathol 8, 325-338.

Mukherjee, O., Wang, J., Gitcho, M., Chakraverty, S., TaylorReinwald, L., Shears, S., Kauwe, J.S., Norton, J., Levitch, D., Bigio, E.H., et al. (2008). Molecular characterization of novel progranulin (GRN) mutations in frontotemporal dementia. Hum Mutat 29, 512-521.

Nakashima-Yasuda, H., Uryu, K., Robinson, J., Xie, S.X., Hurtig, H., Duda, J.E., Arnold, S.E., Siderowf, A., Grossman, M., Leverenz, J. B., et al. (2007). Co-morbidity of TDP-43 proteinopathy in Lewy body related diseases. Acta Neuropathol 114, 221-229.

Neary, D., Snowden, J.S., Northen, B., and Goulding, P. (1988). Dementia of frontal lobe type. J Neurol Neurosurg Psychiatry 51, 353-361.

Neumann, M., Sampathu, D.M., Kwong, L.K., Truax, A.C., Micsenyi, M.C., Chou, T.T., Bruce, J., Schuck, T., Grossman, M., Clark, C.M., et al. (2006). Ubiquitinated TDP-43 in frontotemporal lobar degeneration and amyotrophic lateral sclerosis. Science 314 , 130-133.

Neumann, M. (2007). TDP-43 proteinopathies: a new class of proteinopathies. Future Neurol 2, 549-557.

Ong, C.H., He, Z., Kriazhev, L., Shan, X., Palfree, R.G., and Bateman, A. (2006). Regulation of progranulin expression in myeloid cells. Am J Physiol Regul Integr Comp Physiol 291, 1602-1612.

Phiel, C., Wilson, C., Lee, V., and Klein, P. (2003). GSK-3a regulates production of Alzheimer's disease amyloid- $₫$ peptides. Nature 423 , 435-439.

Pickering-Brown, S.M., Baker, M., Gass, J., Boeve, B.F., Loy, C.T., Brooks, W.S., Mackenzie, I.R., Martins, R.N., Kwok, J.B., Halliday, G.M., et al. (2006). Mutations in progranulin explain atypical phenotypes with variants in MAPT. Brain 129, 3124-3126.

Plowman, G.D., Green, J.M., Neubauer, M.G., Buckley, S.D., McDonald, V.L., Todaro, G.J., and Shoyab, M. (1992). The epithelin precursor encodes two proteins with opposing activities on epithelial cell growth. J Biol Chem 267, 13073-13078.

Rohn, T.T., Head, E., Nesse, W.H., Cotman, C.W., and Cribbs, D.H. (2001). Activation of caspase-8 in the Alzheimer's disease brain. Neurobiol Dis 8, 1006-1016.

Rohn, T.T., Rissman, R.A., Davis, M.C., Kim, Y.E., Cotman, C.W., and Head, E. (2002). Caspase-9 activation and caspase cleavage of tau in the Alzheimer's disease brain. Neurobiol Dis 11, 341-354.

Shankaran, S.S., Capell, A., Hruscha, A.T., Fellerer, K., Neumann, M., Schmid, B., and Haass, C. (2008). Missense mutations in the progranulin gene linked to frontotemporal lobar degeneration with ubiquitin-immunoreactive inclusions reduce progranulin production and secretion. J Biol Chem 283, 1744-1753.

Skibinski, G., Parkinson, N.J., Brown, J.M., Chakrabarti, L., Lloyd, S. L., Hummerich, H., Nielsen, J.E., Hodges, J.R., Spillantini, M.G., Thusgaard, T., et al. (2005). Mutations in the endosomal ESCRTIIIcomplex subunit CHMP2B in frontotemporal dementia. Nat Genet 37, 806-808.

Sleegers, K., Brouwers, N., Maurer-Stroh, S., van Es, M.A., Van Damme, P., van Vught, P.W., van der Zee, J., Serneels, S., De Pooter, T., Van den Broeck, M., et al. (2008). Progranulin genetic variability contributes to amyotrophic lateral sclerosis. Neurology 
71, 253-259.

Sleegers, K., Cruts, M., Van Broeckhoven, C. (2010). Molecular pathways of frontotemporal lobar degeneration. Annu Rev Neurosci 33, 71-88.

Smith, C.J., Anderton, B.H., Davis, D.R., and Gallo, J.M. (1995). Tau isoform expression and phosphorylation state during differentiation of cultured neuronal cells. FEBS Lett 375, 243-248.

Takashima, A., Noguchi, K., Sato, K., Hoshino, T., and Imahori, K. (1993). Tau protein kinase I is essential for amyloid beta-proteininduced neurotoxicity. Proc Natl Acad Sci U S A 90, 7789-7793.

Van Damme, P., Van Hoecke, A., Lambrechts, D., Vanacker, P., Bogaert, E., van Swieten, J., Carmeliet, P., Van Den Bosch, L., and Robberecht, W. (2008). Progranulin functions as a neurotrophic factor to regulate neurite outgrowth and enhance neuronal survival. J Cell Biol 181, 37-41.

van Swieten, J.C., and Heutink, P. (2008). Mutations in progranulin (GRN) within the spectrum of clinical and pathological phenotypes of frontotemporal dementia. Lancet Neurol 7, 965-974.

Verret, L., Jankowsky, J.L., Xu, G.M., Borchelt, D.R., and Rampon, C. (2007). Alzheimer's-type amyloidosis in transgenic mice impairs survival of newborn neurons derived from adult hippocampal neurogenesis. J Neurosci 27, 6771-6780.

Winner, B., Rockenstein, E., Lie, D.C., Aigner, R., Mante, M., Bogdahn, U., Couillard-Despres, S., Masliah, E., and Winkler, J. (2008). Mutant alpha-synuclein exacerbates age-related decrease of neurogenesis. Neurobiol Aging 29, 913-925.

Yang, F., Sun, X., Beech, W., Teter, B., Wu, S., Sigel, J., Vinters, H.V.,
Frautschy, S.A., and Cole, G.M. (1998). Antibody to caspase-cleaved actin detects apoptosis in differentiated neuroblastoma and plaqueassociated neurons and microglia in Alzheimer's disease. Am J Pathol 152, 379-389.

Yoshimura, T., Kawano, Y., Arimura, N., Kawabata, S., Kikuchi, A., and Kaibuchi, K. (2005). GSK-3beta regulates phosphorylation of CRMP-2 and neuronal polarity. Cell 120, 137-149.

Yu, J.Y., Taylor, J., DeRuiter, S.L., Vojtek, A.B., and Turner, D.L. (2003). Simultaneous inhibition of GSK3alpha and GSK3beta using hairpin siRNA expression vectors. Mol Ther 7, 228-236.

Zanocco-Marani, T., Bateman, A., Romano, G., Valentinis, B., He, Z. H., and Baserga, R. (1999). Biological activities and signaling pathways of the granulin/epithelin precursor. Cancer Res 59, 5331-5340.

Zhang, Y.J., Xu, Y.F., Dickey, C.A., Buratti, E., Baralle, F., Bailey, R., Pickering-Brown, S., Dickson, D., and Petrucelli, L. (2007). Progranulin mediates caspase-dependent cleavage of TAR DNA binding protein-43. J Neurosci 27, 10530-10534.

Zhou, J., Gao, G., Crabb, J.W., and Serrero, G. (1993). Purification of an autocrine growth factor homologous with mouse epithelin precursor from a highly tumorigenic cell line. J Biol Chem 268, 10863-10869.

Zhu, J., Nathan, C., Jin, W., Sim, D., Ashcroft, G.S., Wahl, S.M., Lacomis, L., Erdjument-Bromage, H., Tempst, P., Wright, C.D., et al. (2002). Conversion of proepithelin to epithelins: roles of SLPI and elastase in host defense and wound repair. Cell 111, 867878. 